Tác động của CPTPP lên vốn đầu tư trực tiếp nước ngoài trong ngành nông lâm nghiệp và thủy sản

\title{
Impact of the Comprehensive and Progressive Agreement for Trans-Pacific Partnership on FDI of Agriculture, Forestry and Seafood
}

\section{Nguyen Van Chien ${ }^{1}$ \\ Thu Dau Mot University}

Việt Nam đã chính thức gia nhập Hiệp định Đối tác toàn diện và tiến bộ xuyên Thái Bình Dương (CPTPP); hiệp định được kỳ vọng sẽ có tác động tích cực trong thu hút đầu tư trực tiếp nước ngoài và tăng đầu tư vào nông lâm nghiệp và thủy sản và phát triển kinh tế khu vực nông thôn, nơi thu hút gần $40 \%$ lực lượng lao động Việt Nam.

Từ khóa: Đầu tư nước ngoài, CPTPP, ngành nông nghiệp, nông thôn

Vietnam has officially joined the Comprehensive and Progressive Agreement for TransPacific Partnership (CPTPP); the agreement is expected to have positive effects on attracting FDI and increasing investment in the agriculture, forestry and seafood and rural economic development, where has nearly $40 \%$ workforce in Vietnam.

Keywords: Foreign Investment, CPTPP, Agriculture, Rural sector

\section{1. Đầu tư trực tiếp nước ngoài vào ngành nông lâm nghiệp và thủy sản}

Việt Nam thực hiện công cuộc đổi mới năm 1986, phát triển kinh tế từ xuất phát điểm là nước nông nghiệp với khoảng $2 / 3$ dân số sống ở khu vực nông thôn có gắn với hoạt động sản xuất nông lâm nghiệp và thủy sản, hiện nay, trong khi nhóm ngành này đóng góp chưa tới $20 \%$ tổng thu nhập quốc dân.

Ngành nông lâm nghiệp và thủy sản luôn là cứu cánh của nền kinh tế ngay trong thời kỳ khi nền kinh tế gặp trục trặc giai đoạn 1986 - 1990 và giai đoạn gần đây 2011 - 2015, ngành này tạo được nhiều việc làm cho lao động khu vực nông thôn, mặc dù năng suất còn thấp, nhưng khu vực nông lâm nghiệp và thủy sản vẫn duy trì tốc độ tăng trưởng

\footnotetext{
1 chienmpp3@gmail.com
} 
4.06\% giai đoạn 1986 - 2016, hiện nay tốc độ tăng trưởng của ngành đang có xu hướng giảm, chỉ còn $2.9 \%$ năm 2017 và $3.87 \%$ năm 2018 .

Từ một nước bị thiếu đói vào những năm 1975 - 1990, qua quá trình mở cửa Việt Nam đã tự túc được lương thực và xuất khẩu. Xuất khẩu nông và thủy sản được mở rộng từ sau năm 2000, nếu năm 2001 giá trị xuất khẩu nông sản chỉ đạt 3.17 tỷ USD thì đến năm 2010 đạt 19.15 tỷ USD, năm 2018 đạt kỉ lục 40.2 tỷ USD và mục tiêu xuất khẩu 43 tỷ USD vào năm 2019, khẳng định nước ta là quốc gia xuất khẩu nông sản lớn thứ 15 thế giới và thị trường mở tới 180 quốc gia và vùng lãnh thổ, trong đó, 5 thị trường xuất khẩu các mặt hàng nông lâm thủy sản chính của Việt Nam bao gồm Trung Quốc, Mỹ, Nhật Bản, ASEAN và Hàn Quốc; riêng xuất khẩu thủy sản cũng đạt mốc hơn 9 tỷ USD trong năm 2018 và mục tiêu 10 tỷ USD năm 2019.

Chính sách thu hút đầu tư vào ngành nông lâm nghiệp và thủy sản tuy đang được khuyến khích đối với cả nhà đầu tư trong và ngoài nước, đặc biệt việc tham gia các hiệp định thương mại với hi vọng sẽ thu hút được nhiều dòng vốn đầu tư hơn vào ngành này, số doanh nghiệp nghiệp đầu tư vào ngành này đã có những chuyển biến nhưng giá trị đầu tư vào ngành chưa có sự biến đổi đáng kể, doanh nghiệp FDI mới đầu tư $1 \%$ lượng vốn vào ngành, xuất khẩu đến từ khối FDI ngành nông sản và thủy sản cũng hạn chế.

\section{CPTPP và tác động lên ngành nông lâm nghiệp và thủy sản}

Năm 2008, Việt Nam bắt đầu quan tâm tới Hiệp định đối tác xuyên Thái Bình Dương (còn gọi là TPP) và bắt đầu đàm phán, được coi là một hiệp định thương mại tiến bộ nhất của thế kỷ 21 với nhiều tiêu chuẩn cao trong quan hệ thương mại quốc tế và kỳ vọng mang lại nhiều lợi ích kinh tế cho các thành viên. Tuy nhiên, năm 2016 Hoa Kỳ đã chính thức rút khỏi hiệp định, khi đó 11 thành viên còn lại tiếp tục theo đuổi hiệp định theo phiên bản mới không có Hoa Kỳ, được đặt tên là CPTPP - Hiệp định toàn diện và Tiến bộ xuyên Thái Bình Dương. CPTPP có hiệu lực từ ngày 30/12/2018 tại 6 nước Nhật Bản, Mexico, Singapore, New Zealand, Canada và Australia và có hiệu lực vào ngày 14/01/2019 với Việt Nam.

Theo Cục Đầu tư nước ngoài - Bộ Kế hoạch và Đầu tư, kể từ sau khi kết thúc đàm phán hiệp định, đã có nhiều hơn dòng vốn đầu tư nước ngoài vào trong nước, từ 2016 trở lại 
đây vốn FDI đăng ký tăng lên mức kỷ lục 34-35 tỷ USD mỗi năm, tăng 60\% so với giai đoạn từ 2010-2015 mỗi năm chỉ đón nhận khoảng 22-23 tỷ USD. Sau khi Việt Nam phê chuẩn CPTPP vào cuối năm 2018, dòng vốn FDI tiếp tục tăng cao, tính chung 4 tháng đầu năm, FDI đăng ký tăng tới $181 \%$ so với năm 2018, trong khi vốn thực hiện tăng tương ứng $7.5 \%$.

Các dòng vốn FDI chủ yếu đổ vào ngành công nghiệp chế biến, chế tạo và ngành sản xuất, phân phối điện, bán buôn bán lẻ và hoạt động kinh doanh bất động sản. Mặc dù Việt Nam là quốc gia xuất khẩu nhiều nông sản ra thế giới, nhưng FDI vào ngành này mới chỉ đạt $1 \%$ tổng số vốn đầu tư FDI. Lũy kế tới tháng 4/2019, Việt Nam đã thu hút được 349 tỷ USD nhưng ngành nông lâm, thủy sản chỉ thu hút được 3.45 tỷ USD (ứng với tỷ trọng $1 \%$ ), thấp hơn rất nhiều một số ngành khác như ngành công nghiệp chế biến chế tạo 203 tỷ USD (ứng với tỷ trọng 58.2\%), ngành bất động sản 58.2 tỷ USD (ứng với tỷ trọng 16.7\%). Ngay một số ngành khác như ngành giáo dục, ngành khai khoáng, thông tin truyền thông cũng thu hút FDI với tỷ trọng khiêm tốn, nhưng vẫn cao hơn nhiều ngành nông lâm và thủy sản.

Để đánh giá tác động của CPTPP, đặc biệt sự kỳ vọng vào khi tham gia CPTPP Việt Nam sẽ thu hút được nhiều dòng vốn FDI vào ngành nông lâm nghiệp và thủy sản, dựa theo số liệu Cục đầu tư nước ngoài (Bộ Kế hoạch và đầu tư) công bố, thấy rằng tỷ trọng thu hút FDI vào nhóm ngành này ngày càng giảm, liên tục từ năm 2016 cho đến nay. Cụ thể, giai đoạn 2016 - 2018, FDI vào ngành nông lâm nghiệp, thủy sản chỉ chiếm $0.4 \%$ - $0.5 \%$ tổng FDI của cả nước, riêng trong 4 tháng đầu năm FDI tỷ trọng này tụt giảm rất mạnh chỉ còn $0.1 \%$, mức rất thấp so với các năm trước đó. Kết quả thu hút FDI vào ngành nông, thủy sản xem Hình 1 dưới đây:

\section{Hình 1. Tỷ trọng thu hút FDI vào một số ngành kinh tế kể từ sau kết thúc đàm phán hiệp định}




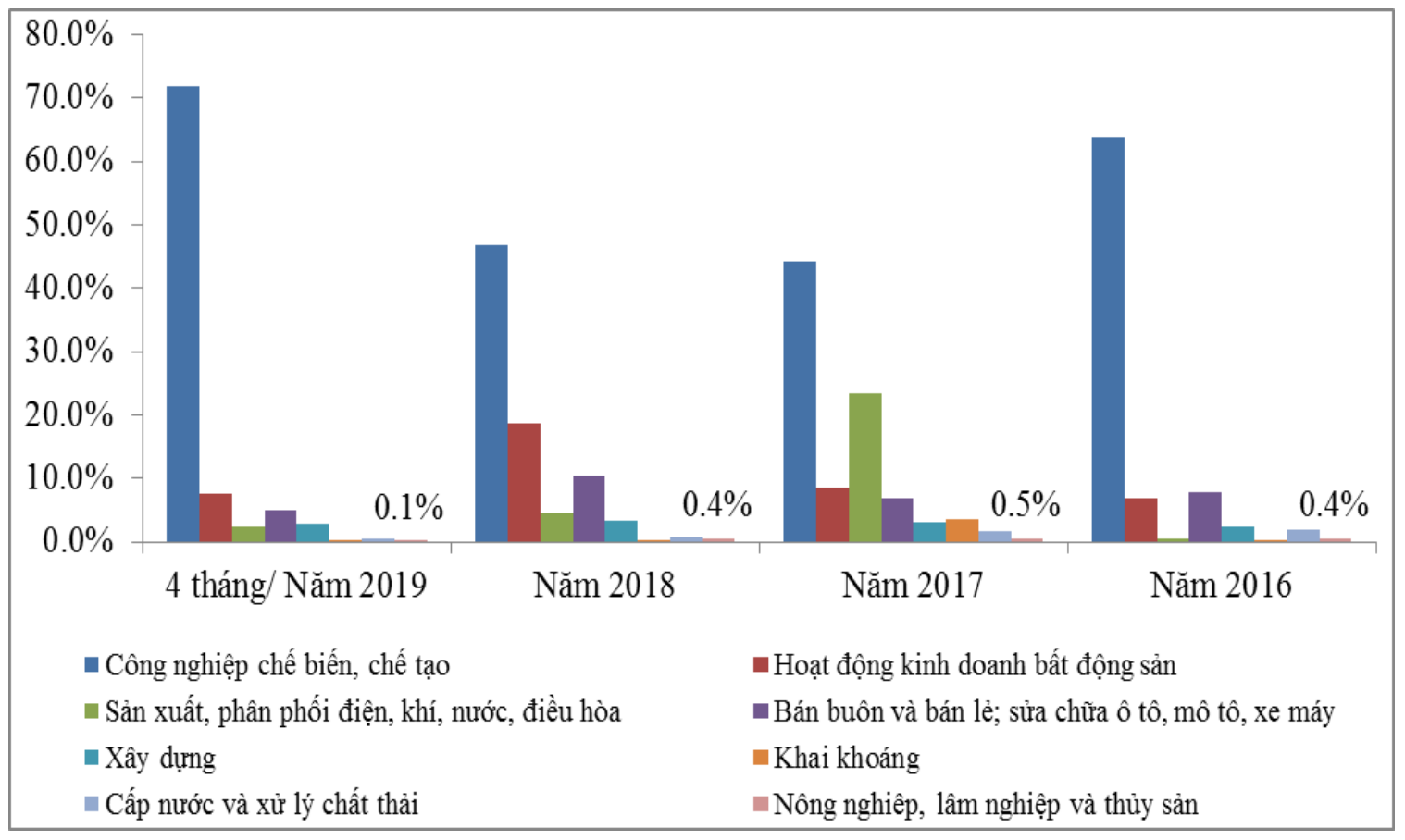

Nguồn: Bộ Kế hoạch và Đầu tư, Cục đầu tư nước ngoài (2019)

Bằng chứng cho thấy, tác động của CPTPP về việc thu hút FDI vào ngành nông lâm nghiệp và thủy sản là không có; đặc thù ngành nông lâm nghiệp và thủy sản Việt Nam sản xuất manh mún, nhỏ lẻ, giá trị gia tăng thấp, sự kỳ vọng tham gia CPTPP sẽ có tác động tích cực lên sự đầu tư vào ngành nông nghiệp đã chưa xảy ra, kể cả trong ngắn hạn. Hơn nữa, Việt Nam cũng chưa thu hút được dự án FDI lớn vào ngành nông lâm nghiệp và thủy sản để hình thành nền sản xuất hàng hóa lớn, giá trị đầu tư bình quân vào ngành nông lâm nghiệp, thủy sản chỉ 7 triệu USD/dự án, thấp hơn nhiều so với giá trị đầu tư bình quân chung là 12.4 triệu USD/dự án. Tính tới tháng 3 năm 2019, ngành nông lâm nghiệp, thủy sản chỉ thu hút được 493 dự án FDI, với số vốn ở mức 3.5 tỷ USD, tương ứng với $1.76 \%$ số dự án và $1 \%$ số vốn đầu tư vào Việt Nam tính từ thời kỳ đổi mới.

Đối với hoạt động xuất khẩu, CPTPP kỳ vọng góp phần mở rộng xuất khẩu hàng hóa Việt Nam sang 10 nước thành viên trong khối, CPTPP là thị trường của 463 triệu dân trên 3 châu lục, GDP đạt khoảng 10 nghìn tỷ USD, chiếm 13\% GDP toàn cầu. Trong ngắn hạn, Việt Nam kỳ vọng vào sự mở rộng xuất khẩu ngành thủy hải sản và ngành gỗ khi thuế suất ngành này giảm mạnh ngay trong năm 2019 tại thị trường mới ở Peru, Mexico và Canada, bên cạnh thị trường truyền thống ở Singapore, Úc, ...; những mặt hàng nông 
sản như hạt điều, nhãn, vải và thanh long của Việt Nam sẽ được vào thị trường Peru với mức thuế NK $0 \%$ thay vì $9 \%$ như hiện nay; các măt hàng thủy hải sản được giảm thuế mạnh vào thị trường Nhật Bản. Bằng chứng cho thấy rằng mặc dù tỷ trọng xuất khẩu của khối FDI so với xuất khẩu của Việt Nam ngày càng tăng, từ mức 47.2\% năm 2000 lên đến 54.2\% năm 2010 và tăng trên 71.7\% năm 2018 (Tổng cục thống kê, 2018), xuất khẩu Việt Nam ngày càng phụ thuộc vào khối này. Tuy nhiên, xuất khẩu của khối FDI trong ngành nông nghiệp không được cải thiện mặc dù xuất khẩu của khối doanh nghiệp trong nước có sự tăng trưởng 9.1\% năm 2018. Về mặt thị trường xuất khẩu, thị trường chính cho xuất khẩu các mặt hàng nông sản chính vẫn là các quốc gia ngoài CPTPP bao gồm Trung Quốc, Mỹ, ASEAN và Hàn Quốc chiếm thị phần lần lượt là 22,9\% (giá trị tăng $3,6 \%$ so với năm 2017), 17,9\% (tăng 9,4\%), 10,64\% (tăng $11,0 \%$ ) và $6,9 \%$ (tăng $29,4 \%$ so với năm 2017). Xuất khẩu mặt hàng nông thủy sản vào CPTPP đã có sự mở rộng tại thị trường Nhật Bản (giá trị tăng 7.1\%) và thị trường Malaysia (sản phẩm gỗ tăng $88 \%$, café tăng $50 \%$, giấy và sản phẩm giấy tăng $48.4 \%$, thức ăn gia súc tăng $25.45 \%$ ), nhưng xuất khẩu vào một số thành viên khác trong CPTPP như Peru, Úc, Mexico... chưa thực sự có sự cải thiện.

CPTPP mang lại nhiều thách thức đối với nhiều lĩnh vực, ngành hàng của Việt Nam, trong đó có nông, thủy sản. Theo hiệp định CPTPP, ngay khi có hiệu lực, nhiều mặt hàng nông sản xuất khẩu của các nước thành viên được giảm thuế, thuế suất đối với thủy hải sản giảm mạnh và Việt Nam cũng phải thực hiện các cam kết đó. Do năng lực cạnh tranh của các mặt hàng nông sản, sản phẩm chăn nuôi trong nước chưa cao, nên ngành nông nghiệp sẽ chịu sức ép đáng kể.

Hơn nữa, Việt Nam phải thực hiện nhiều cải cách về luật pháp để mở cửa đầu tư, cải cách về vấn đề lao động và công đoàn, về bảo vệ, bảo hộ bản quyền, về minh bạch, giảm rủi ro đầu tư thông qua các cam kết về bảo hộ đầu tư. Trong thực tế nền nông nghiệp nước ta dựa trên số lượng nông hộ với quy mô sản xuất nhỏ, manh mún và phân tán, chưa hình thành nền sản xuất lớn, khó áp dụng khoa học công nghệ trong sản xuất, khi tham gia CPTPP với việc mở toang cánh cửa cho hàng hóa nhập khẩu xâm nhập vào thị trường trong nước, điều đó cho thấy ngành nông nghiệp dễ bị tổn thương hơn so với các ngành kinh tế khác. Bên cạnh đó, theo viện năng suất Việt Nam (2018) năm 2017 năng suất 
ngành nông lâm nghiệp và thủy sản thấp nhất trong các nhóm ngành kinh tế, chỉ đạt 39.7 triệu đồng, năng suất ngành nông nghiệp chỉ tương ứng với $29.7 \%$ năng suất của ngành công nghiệp (133.7 triệu đồng) và 31\% ngành dịch vụ (125.7 triệu đồng), 43\% năng suất chung của nền kinh tế (92.1 triệu đồng), mặc dù ngành nông nghiệp có năng suất thấp nhưng đang tạo số lượng việc làm lớn với khoảng $40 \%$ lực lượng lao động của cả nước, góp phần đảm bảo an sinh xã hội.

Một thách thức khác đặt ra đối với doanh nghiệp trong nước là: để được hưởng ưu đãi đối với xuất khẩu vào các quốc gia thành viên $\mathrm{CPTPP}$ này thì nguồn nguyên liệu đầu vào phải có nguồn gốc xuất xứ trong nội khối. Hiện nay các doanh nghiệp nông và thủy hải sản lúng túng không biết chứng minh xuất xứ hàng hóa như thế nào, thực tế khi chứng minh xuất xứ, các doanh nghiệp thường dựa vào một số hóa đơn mua hàng, hóa đơn VAT, nhưng thực chất hóa đơn này chỉ thể hiện về tài chính trong giao dịch chứ chưa thể chứng minh xuất xứ cho sản phẩm, trong khi quy tắc xuất xứ là cơ sở để được hưởng ưu đãi thuế quan. Bên cạnh đó, tham gia CPTPP có Việt Nam và 10 đối tác đều là các nền kinh tế phát triển hơn Việt Nam, quá trình xuất nhập khẩu hàng hóa nông sản, thủy sản sẽ phải đứng trước thử thách "hàng rào kỹ thuật", bởi thông thường những quốc gia phát triển thường đòi hỏi với những yêu cầu khắt khe về nhập khẩu, về chất lượng hàng hóa, về kiểm duyệt quy trình sản xuất và bảo quản hàng hóa nghiêm ngặt.

\section{Một số giải pháp nâng cao hiệu quả ngành nông lâm nghiệp và thủy sản khi tham gia hiệp định CPTPP}

Tham gia hiệp định CPTPP, Việt Nam ngày càng hội nhập sâu vào nền kinh tế toàn cầu, thông qua quá trình mở cửa các hoạt động kinh tế, đi kèm với các quy định về cải cách quan hệ lao động, nguồn gốc xuất xứ hàng hóa, cải cách hệ thống luật pháp và thể chế. Mặc dù được kì vọng mang lại nhiều lợi ích cho nền kinh tế trong nước, nhưng trong nhiều ngành nghề, tồn tại nhiều cơ hội cũng như thách thức. Ngành nông lâm nghiệp, thủy sản đứng trước thách thức phải tái cơ cấu trong điều kiện ngành có năng suất thấp nhất trong các ngành kinh tế, không những thế, ngành đang tạo việc làm cho tới $40 \%$ lực lượng lao động của cả nước, trong khi lực lượng lao động trong ngành này chủ yếu sống ở khu vực nông thôn, cuộc sống còn khó khăn, dễ rơi vào vòng xoáy của đói nghèo. Tái 
cơ cấu ngành nông nghiệp là nhiệm vụ sống còn để phát triển kinh tế khu vực nông thôn. Một số giải pháp được đề xuất:

Thư nhất, tái cơ cấu ngành thực hiện song hành với chính sách tái cấu trúc nền kinh tế và thay đổi mô hình tăng trưởng mà Đảng, Nhà nước đang kêu gọi. Việt Nam đã từng thúc đẩy tăng trưởng dựa trên sự mở rộng vốn, nhiều năm đã duy trì tốc độ tăng trưởng tín dụng cao và vay nợ để mở rộng đầu tư, nhưng đến nay sự phát triển theo mô hình tăng trưởng cũ đã đạt tới hạn. Mục tiêu tái cơ cấu nền kinh tế nói chung và ngành nông nghiệp riêng theo mô hình tăng trưởng mới, dựa trên sự phát triển kinh tế theo chiều sâu, đầu tư vào khoa học công nghệ và tận dụng sự phát triển khoa học kỹ thuật, đặc biệt những tiến bộ trong cuộc cách mạng công nghiệp 4.0. Khi sản xuất được sản phẩm có chất lượng cao, đồng nghĩa với các sản phẩm sẽ dễ dàng đáp ứng yêu cầu của các nước trong nội khối CPTPP và các đối tác khác, vượt qua nhiều rào cản kĩ thuật khắt khe, tái cơ cấu chỉ thực hiện được bằng cách tăng đầu tư vào ngành công nghiệp chế biến, đầu tư vào chất lượng sản phẩm, từ đó tạo giá trị gia tăng cao hơn cho sản phẩm nông nghiệp, đảm bảo sự phát triển bền vững của thị trường xuất khẩu và thu nhập của người lao động trong ngành nông nghiệp.

Thư hai, Nhà nước cần tạo cơ chế chính sách phù hợp để kêu gọi các doanh nghiệp đầu đàn, doanh nghiệp FDI và doanh nghiệp nội địa lớn đầu tư vào doanh nghiệp nông nghiệp. Đặc điểm ngành nông nghiệp gắn với sản xuất thô, quy mô nhỏ lẻ, xuất khẩu ở dạng thô, dẫn tới giá trị gia tăng thấp. Doanh nghiệp lớn sẽ mang công nghệ hiện đại vào ngành, thời gian qua một số doanh nghiệp lớn đã bắt đầu đầu tư vào nông nghiệp như Vingroup thông qua Công ty TNHH Đầu tư Phát triển Sản xuất Nông nghiệp VinEco, Hoàng Anh Gia Lai, đã áp dụng công nghệ hiện đại, tạo giá trị gia tăng cao hơn cho các sản phẩm nông nghiệp. Ngành thủy hải sản mặc dù đã có một số công ty lớn tại ĐBSCL, nhưng vẫn còn tồn tại một số hạn chế trong quá trình khai thác, để tiến tới phát triển bền vững thì công tác đánh bắt và khai thác thủy sản, cần gắn liền với hoạt động nuôi trồng và phát triển con giống, Cộng đồng Kinh tế Châu Âu - EU hiện còn chưa gỡ thẻ vàng đối với mặt hàng thủy sản cũng do những sai phạm trong hoạt động này.

Thư $b a$, các sản phẩm nông nghiệp và thủy sản không những chỉ xuất khẩu vào nội khối CPTPP mà còn tới các thị trường truyền thống như Trung Quốc, Hàn Quốc, ASEAN và 
thị trường Mỹ, cũng như cả thị trường nội địa. Hiện nay xu hướng bảo hộ mậu dịch ngày càng tăng, nhất là xung đột thương mại Mỹ- Trung chưa có dấu hiệu hạ nhiệt sau khi Mỹ đã áp thuế nhập khẩu từ 10\% lên 25\% đối với 200 tỉ USD hàng hóa từ Trung Quốc vào ngày 10/5/2019 vừa qua đã làm cho căng thẳng thương mại leo thang, tác động ít nhiều tới Việt Nam. Là một trong những nền kinh tế có độ mở cao nhất thế giới, lên tới 200\%, Việt Nam rất dễ bị tác động và chịu rủi ro trước những biến động trên thị trường toàn cầu. Do vậy, một mặt thúc đẩy xuất khẩu hàng hóa thì các sản phẩm nông sản, thủy sản cũng phải quan tâm tới thị trường nội địa, bên cạnh đa dạng hóa thị trường xuất khẩu và mở rộng thị trường mới.

\section{Tài liệu tham khảo:}

1. Bộ Kế hoạch và Đầu tư (2019), 'Tình hình thu hút đầu tư trực tiếp nước ngoài', nguồn truy cập https://dautunuocngoai.gov.vn/chuyenmuc/172/So-lieu-FDI-hang-thang

2. Bộ Công thương (2019), 'Lời văn của Hiệp định đối tác toàn diện và tiến bộ xuyên Thái Bình Dương (CPTPP)'.

3. Nguyen, V. (2020). Human capital, capital structure choice and firm profitability in developing countries: An empirical study in Vietnam. Accounting. 6(2), 127-136. doi: $10.5267 / j$. ac. 2019.11 .003

4. Nguyen, V.C. (2020). Energy consumption, income, trading openness, and environmental pollution: Testing environmental Kuznets curve hypothesis. Journal of Southwest Jiaotong University. 55(1), 1-10. https://doi.org/10.35741/issn.02582724.55.1.6

5. Nguyen, V., \& Do, T.T. (2020). Impact of exchange rate shocks, inward FDI and import on export performance: a cointegration analysis. Journal of Asian Finance, $\begin{array}{llll}\text { Economics and } & \text { Business, }\end{array}$ DOI:https://doi.org/10.13106/jafeb.2020.vol7.no4.163

6. Tran, V.D., \& Van, N. (2013). Enhancing of the quality of public policy promulgation in Vietnam. Journal of State and Law, 371, 28-35. Retrieved at http://www.vjol.info/index.php/ssir/article/viewArticle/16224

7. Van, N. (2019). Improving quality of FDI attraction into Vietnam for the coming period - From the institutional view. Review of Finance, ISSN 2615-8973, 704, 1821. Available at https://ssrn.com/abstract $=3569549$

8. Van, N. (2020). Trade liberalization, economic reforms and foreign direct investment - A critical analysis of the political transformation in Vietnam. International Journal of Advanced Science and Technology, 29 (3), 6837 - 6850. Available at https://ssrn.com/abstract=3566751

9. Viện năng suất Việt Nam (2018). 'Báo cáo năng suất Việt Nam 2017'. 